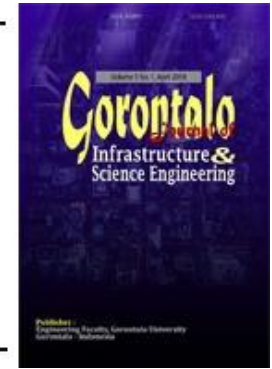

\title{
Analisa Agregat Halus Pasir Zona III Dengan Agregat Kasar Ukuran 20 mm Dan 40 mm Untuk Uji Kuat Tekan Mutu Beton Pada Campuran Beton Normal
}

\author{
Nasir Bumulo1) dan Nur Windawaty Rusnadin ${ }^{2)}$ \\ 1)Teknik Sipil, Fakultas Teknik Universitas Gorontalo \\ e-mail : nasirbumulo2015@gmail.com \\ 2)Teknik Sipil, Fakultas Teknik Universitas Gorontalo \\ e-mail : windawrusnadin37@gmail.com
}

\begin{abstract}
Concrete is a construction material that is widely used in building structutre work in indonesia becouse it has many benefits. Its compactness and cooperation arragement is very influential toward the compressive strength. One factor is the compectness of concrete fine aggregate and coarse aggregate. The aim of this research was to find out compessive strength of concrete at 28 days using sand material zone III with pebbles the size of $20 \mathrm{~mm}$ and $40 \mathrm{~mm}$ in a normal concrete mix.The reseach was using the quantitaive testing method. The independent variable of this research was the composition of the mixture, and dependent variable was in the form of concrete quality. The control variable was the material being used. The data collection was done by conducting laboratory testing based on SNI and PBI. The data analysis was done by calculating the average of the test results are then compered with SNI and PBI.The result of concrete research with sand material of zone III and gravel of $20 \mathrm{~mm}$ and $40 \mathrm{~mm}$ was observed at 28 days old showed a compressive strength value of $311,89 \mathrm{Kg} / \mathrm{cm} 2$. Then the concrete sample with sand material of zone III and pebble size $40 \mathrm{~mm}$ shows the value of compressive strength of $334,46 \mathrm{Kg} / \mathrm{cm} 2$. From this result, it can be concluded that the mixture of sand zone III with gravel measuring $40 \mathrm{~mm}$ has a value of concrete compressive strength greater than 20 $\mathrm{mm}$.
\end{abstract}

Keywords : Superplasticizer, Lime, Strong Concrete, The Concrete Age

\section{PENDAHULUAN}

Beton terbentuk dari campuran agregat halus, agregat kasar, semen dan air dengan perbandingan tertentu. Beton merupakan suatu bahan konstruksi yang banyak digunakan pada pekerjaan struktur bangunan di Indonesia karena banyak keuntungan yang diberikan diantaranya adalah bahan-bahan pembentuknya mudah diperoleh, mudah dibentuk, mampu memikul beban yang berat, tahan terhadap temperatur yang tinggi, biaya pemelihaaan kecil. Yang 
perlu disadari benar dalam pembuatan beton disini ialah perancangan komposisi bahan pembentuk beton, yang merupakan penentu kualitas beton, yang berarti pula kualitas sistem struktur total.

Beton sejak dulu dikenal sebagai material dengan kekuatan tekan yang memadai, mudah dibentuk, mudah diproduksi secara lokal, relatif kaku, dan ekonomis. Tapi di sisi lain, beton juga menunjukan banyak keterbatasan baik dalam proses produksi maupun sifat-sifat mekaniknya, sehingga beton pada umunya hanya digunakan untuk konstruksi dengan ukuran kecil dan menengah.Berbagai penelitian dan percobaan dibidang teknologi beton dilakukan sebagai upaya untuk meningkatkan kualitas beton. Teknologi bahan dan teknik-teknik pelaksanaan yang diperolehdari hasil penelitian dan percobaan tersebut dimaksudkan untuk menjawabtuntutan yang semakin tinggi terhadap pemakaian beton serta mengatasi kendala-kendala yang sering terjadi pada pengerjaan dilapangan.

Untuk mempelajari seluruh perilaku elemen gabungan pembentuk beton diperlukan pengetahuan tentang karakteristik masing-masing komponen pembentuk beton yaitu semen, agregat halus, agregat kasar dan air. Kekuatan beton pada umur tertentu tergantung pada perbandingan agregat kasar.Kekompakan dan kerjasama susunan bahan beton sangat berpengaruh untuk memenuhi kuat tekannya. Salah satu faktor kekompakan beton adalah agregat halus. Dalam penelitian ini agregat halus menggunakan pasir zona III dan agregat kasar berupa kerikil ditinjau dari ukuran.

Tujuan penelitian ini adalah untuk mengetahui seberapa besar pengaruh campuran agregat halus pasir zona III dengan kerikil ukuran $20 \mathrm{~mm}$ dan $40 \mathrm{~mm}$ terhadap kuat tekan beton.

\section{KAJIAN TEORI}

\subsection{BETON}

Beton adalah sebuah bahan bangunankomposit yang terbuat dari kombinasi agregat dan pengikat semen.Bentuk paling umum dari beton adalah beton semen Portland, yang terdiri dari agregat mineral (biasanya kerikil dan pasir),semendanair.Biasanya dipercayai bahwa beton mengering setelah pencampuran dan peletakan.Sebenarnya, beton tidak menjadi padat karena air menguap, tetapi semen berhidrasi, mengelem komponen lainnya bersama dan akhirnya membentuk material seperti-batu. Beton digunakan untuk membuat perkerasan jalan, struktur bangunan, fondasi, jalan, jembatan penyeberangan, struktur parkiran, dasar untuk pagar/gerbang, dan semen dalam bata atau tembok blok.

Membuat beton sebenarnya tidaklah sederhana hanya sekedar mencampurkan bahan-bahan dasarnya untuk membentuk campuran yang plastis sebagaimana sering terlihat pada pembuatan bangunan yang sederhana. Tetapi jika ingin membuat beton yang baik, dalam arti memenuhi persyaratan yang lebih ketat karena tuntutan yang lebih tinggi, maka harus diperhitungkan dengan seksama cara-cara memperoleh adukan beton segar yang baik dan menghasilkan beton keras yang baik pula. Beton segar yang baik ialah beton segar yang dapat diaduk, dapat diangkut, dapat dituang dan dapat dipadatkan, tidak cenderung untuk terjadi pemisahan kerikil dari adukan maupun pemisahan air dan semen adukan. Beton keras yang baik adalah beton yang 
kuat, tahan lama, kedap air, tahan aus, dan kembang susutnya kecil. (Paul Nugraha Antoni, 2007).

Agar dihasilkan kuat desak beton yang sesuai dengan rencana diperlukan mix design untuk menentukan jumlah masing-masing bahan susun yang dibutuhkan. Disamping itu, adukan beton harus diusahakan dalam kondisi yang benar-benar homogen dengan kelecakan tertentu agar tidak terjadi segregasi.Selain perbandingan bahan susunnya, kekuatan beton ditentukan oleh padat tidaknya campuran bahan penyusun beton tersebut.Semakin kecil rongga yang dihasilkan dalam campuran beton, maka semakin tinggi kuat desak beton yang dihasilkan.

Semen dan air dalam adukan beton membuat pasta yang disebut pasta semen. Adapun pasta semen ini selain berfungsi untuk mengisi pori-pori antara butiran agregat halus dan agregat kasar juga mempunyai fungsi sebagai pengikat sehingga terbentuk suatu massa yang kompak dan kuat.

Ketika semen dan air dicampur, partikel-partikel semen cenderung berkumpul menjadi gumpalan yang dikenal sebagai gumpalan semen.Penggumpalan mencegah pencampuran antara semen dan air yang menghasilkan kehilangan kemampuan kerja (loss of workability) dari campuran beton sebagaimana hal tersebut mencegah campuran hidrasi yang sempurna. Ini berarti bahwa pengurangan kekuatan potensial penuh dari pasta semen akan ditingaktkan. Pada beberapa kejadian dalam 28 hari perawatan hanya $50 \%$ kandungan semen sudah terhidrasi.

\subsection{SEMEN}

Semen adalah suatu jenis bahan yang memiliki sifat adhesi dan kohesi, yang memungkinkan melekatnya fragmen-fragmen mineral menjadi suatu massa yang padat. Semen yang dimaksudkan untuk konstruksi beton adalah bahan yang jadi dan mengeras dengan adanya air, yang dinamakan semen hidrolik (hydraulic cement). Semen semacam ini berbahan utama silikat atau pasir silika dan campuran dari batu kapur dan tanah liat yang digerinda, dicampur, dibakar di dalam pembakaran kapur (klin), dan kemudian dihancurkan menjadi bubuk / tepung. Dalam penggunaannya, semen semacam ini secara kimia dicampur dengan air membentuk massa yang mengeras.

Semen jika dicampur dengan air akan membentuk adukan yang disebut pasta semen, jika dicampur dengan agregat halus dan air, maka akan terbentuk adukan yang disebut mortar, jika ditambah lagi dengan agregat kasar akan terbentuk adukan yang biasa disebut beton. Dalam campuaran beton, semen bersama air sebagai kelompok aktif sedangkan pasir dan kerikil sebagai kelompok pasif adalah kelompok yang berfungsi sebagai pengisi.

Semen Portland atau semen Portland pozzolan digunakan untuk bahan beton, berupa semen hidrolik yang berfungsi sebagai bahan perekat bahan. Dengan jenis semen tersebut diperlukan air guna berlangsungnya reaksi kimiawi pada proses hidrasi. Semen Portland pada awalnya ditemukan di dekat kota Dorset, Inggris oleh Joseph Aspdin, seorang tukang batu kebangsaan Inggris pada tahun 1824. Dinamakan semen Portland karena semen yang dihasilkannya mempunyai warna serupa dengan tanah liat alam di pulau Portland. 


\subsection{AIR}

Air adalah bahan yang digunakan untuk adukan beton, karena itu air mempunyai pengaruh yang penting dalam menentukan kekuatan dan kemudahan pelaksanaan pencampuran beton. Air yang dapat diminum dapat pula digunakan untuk air adukan beton, akan tetapi yang dapat digunakan untuk adukan beton tidak berarti dapat diminum.

\subsection{AGREGAT}

Agregat adalah bahan granular seperti pasir, kerikil, dan batu pecah atau kombinasi dari bahan-bahan tersebut.Agregat dibedakan dalam agregat alam dan buatan.Agregat alam berasal dari batu alam atau berasal dari penghancuran alami dari batuan alam, sedangkan agregat buatan diperoleh dari industri pemecah batu.Menurut beratnya agregat dapat dibagi menjadi agregat berat, agregat normal, dan agregat ringan.Agregat alam berat digunakan untuk pembuatan beton berat, agregat alam normal untuk pekerjaan beton yang umum, dan agregat alam ringan untuk pembuatan beton ringan.

Agregat terdiri atas butiran-butiran yang beraneka ragam dari ukuran kecil sampai besar. Jika ukuran butiran ini diuraikan ke dalam kelompok dengan ukurannya tertentu, maka dapat diperoleh suatu pembagian butiran yang terdiri dari butiran yang sama besarnya atau antara batasan ukuran tertentu. Untuk menguraikan besar butiran ke dalam fraksi digunakan ayakan (sieve), dan dari hasil pengayakan diperoleh gambaran mengenai susunan butiran dari agregat tersebut menjadi agregat halus atau agregat kasar.

\subsection{AGREGAT HALUS}

Agregat halus merupakan pengisi yang berupa pasir.Agregat halus yang baik harus bebas dari bahan organik dan lempung.Pasir yang digunakan dalam pencampuran beton jika dilihat dari sumberya dapat berasal dari sungai ataupun dari galian tambang (quarry).

Tabel 1 :Analisa Saringan Agregat Halus

\begin{tabular}{|c|c|c|c|c|}
\hline Lubang Ayakan & \multicolumn{4}{|c|}{ Persen bahan butiran yang lewat ayakan } \\
\cline { 2 - 5 }$(\mathbf{m m})$ & Zona 1 & Zona 2 & Zona 3 & Zona 4 \\
\hline 10 & 100 & 100 & 100 & 100 \\
\hline 4,8 & $90-100$ & $90-100$ & $90-100$ & $95-100$ \\
\hline 2,4 & $60-95$ & $75-100$ & $85-100$ & $95-100$ \\
\hline 1,2 & $30-70$ & $55-90$ & $75-100$ & $90-100$ \\
\hline 0,6 & $15-34$ & $35-59$ & $60-79$ & $80-100$ \\
\hline 0,3 & $5-20$ & $8-30$ & $12-40$ & $15-50$ \\
\hline 0,15 & $0-10$ & $0-10$ & $0-10$ & $0-15$ \\
\hline \multicolumn{5}{|c}{ Sumber : Buku Teknologi Bahan 1, Hal 32-33 }
\end{tabular}

\subsection{AGREGAT KASAR}

Agregat kasar apabila ukurannya sudah melebihi $6 \mathrm{~mm}$. Sifat agretgat kasar mempengaruhi kekuatan akhir beton keras dan daya tahannya terhadap disentegrasi beton, cuaca dan efek-efek perusak lainnya.Agrekat kasar mineral ini harus bersih dari bahan-bahan organik dan harus mempunyai ikatan yang baik dengan gel semen.Agregat kasar ini biasanya berupa kerikil, spilit, batu pecah, kricak dan lainnya. 
Tabel 2 :Analisa Saringan Agregat Kasar

\begin{tabular}{|c|c|c|c|}
\hline \multirow{2}{*}{$\begin{array}{c}\text { Ukuran } \\
\text { Saringan } \\
\text { (mm) }\end{array}$} & \multicolumn{3}{|c|}{$\begin{array}{c}\text { Persentase agregat yang } \\
\text { lolos saringan (\%) }\end{array}$} \\
\cline { 2 - 4 } & \multicolumn{3}{|c|}{ Gradasi Agregat } \\
\cline { 2 - 4 } & $\mathbf{4 0} \mathbf{~ m m}$ & $\mathbf{2 0} \mathbf{~ m m}$ & $\mathbf{1 0} \mathbf{~ m m}$ \\
\hline 76 & 100 & - & - \\
\hline 38 & $95-100$ & 100 & - \\
\hline 19 & $35-70$ & $95-100$ & 100 \\
\hline 9,6 & $10-40$ & $30-60$ & $50-85$ \\
\hline 4,8 & $0-5$ & $0-10$ & $0-10$ \\
\hline
\end{tabular}

Sumber : Buku Teknologi Bahan 1, Hal 32-33

\subsection{WORKABILITY}

Workability adalah kemampuan untuk dilaksanakan atau dikerjakan, yang meliputi bagaimana beton itu mudah untuk dibawa dan ditempatkan di manamana, mudah dikerjakan, mudah dipadatkan, dan mudah untuk dilakukan finishing. Workability beton dapat diuji dengan melakukan slump test.

\subsection{PERENCANAAN CAMPURAN BETON}

a. Menetukan kuat tekan karateristik beton sesuai dengan rencana $(\sigma ' b k)$ dengan persamaan.

$\sigma^{\prime} b k=\sigma^{\prime} b m-(1,645 \times$ s $)$

b. Memperkiran standar deviasi rencana beton,persamaan

$$
\mathrm{s}=\sqrt{\frac{\sum_{1}^{\mathrm{N}}\left(\delta^{\delta} \mathrm{b}-\delta^{\circ} \mathrm{bm}\right)^{2}}{\mathrm{~N}-1}}
$$

c. Menentukan nilai tambah atau margin dari beton yang direncanakan. Nilai batas $=1.64 \times$ standar deviasi.

d. Menentukan kuat tekan beton rata-rata yang direncanakan dengan persamaan $\sigma^{\prime} b m=\sigma^{\prime} b / N$

e. Menetukan jenis atau tipe semen yang akan digunakan dalam pembuatan beton.

f. Menetukan tipe agregat halus dan kasar yang akan digunakan dalam pembuatan beton.

g. Menentukan faktor air semen.

\subsection{KUAT TEKAN BETON}

Kekuatan tekan beton merupakan salah satu kinerja utama beton. Kekuatan tekan adalah kemampuan beton untuk menerima gaya tekan pesatuan luas. Walaupun dalam beton terdapat tegangan tekan tarik yang kecil, diasumsikan bahwa semua tegangan tekan didukung oleh beton tersebut. Penentuan kekuatan tekan dapat dilakukan dengan menggunakan alat uji tekan dan benda uji bebentuk silinder dengan prosedur uji ASTN C-39 atau kubus dengan porsedur BS-1881 part 115;part 116 pada umur 28 hari. 


\subsection{FAKTOR YANG MEMPENGARUHI KUAT TEKAN}

a. Pemilihan Bahan

Proporsi campuran yang optimum harus ditentukan dengan mempertimbangkan karakteristik semen portland dan Kapur, kualitas agregat, proporsi pasta, interaksi agregat pasta, macam dan jumlah bahan campuran tambahan dan pelaksanaan pengadukan. Hasil evaluasi tentang semen portland, Kapur, bahan campuran tambahan, agregat dari berbagai sumber, serta berbagai macam proporsi campuran, dapat digunakan untuk menentukan kombinasi bahan yang optimum.

b. Metode Pengujian

Metode pengujian yang digunakan adalah berdasarkan SNI, kecuali jika terdapat indikasi adanya penyimpangan akibat karakteristik beton kekuatan tinggi tersebut. Kekuatan potensial untuk satu set bahan tertentu dapat ditetapkan hanya bila benda uji telah dibuat dan diuji pada kondisi standar. Minimum dua benda uji harus diuji untuk setiap umur dan kondisi uji.

\section{METODE PENELITIAN}

Metode penelitian yang digunakan adalah metode uji laboratorium. Bahanbahan material yang akan digunakan ialah material batu alam agregat kasar (kerikil) yang berasal dari sungai Bionga dan agregat halus (pasir zona III) yang berasal dari sungai Pilohayanga Kabupaten Gorontalo. Pada dasarnya metode penelitian merupakan cara ilmiah guna mendapatkan data dengan tujuan tertentu. Metodelogi yang penulis lakukan adalah dengan cara membuat benda uji di Laboraturium, kemudian penulis mengujinya dengan cara tekan dengan umur beton 28 hari.

Gambar 1 : Lokasi Pengambilan Material

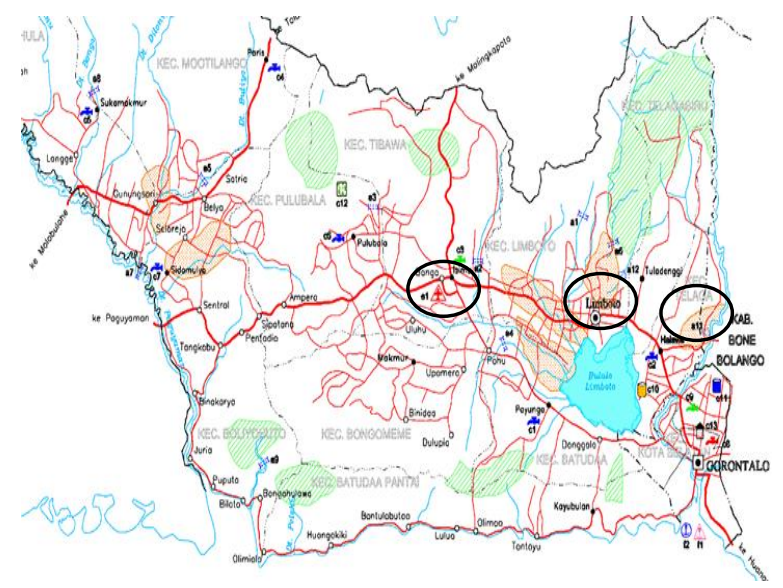

\subsection{BAHAN BAKU}

a. SemenPortlandtype 1 merk Tonasa.

b. Agregat Kasar (kerikil) ukuran $20 \mathrm{~mm}$ dan $40 \mathrm{~mm}$

c. Agregat halus (pasir zona III)

d. Air dari laboratorium 


\subsection{ALAT}

a. Timbangan

b. Satu set alat pemeriksaan agregat (piring, piknometer, oven, saringan agregat serta mesin shieve shaker untuk mengayak saringan).

c. Mesin aduk beton (molen).

d. Kerucut Abrahams

e. Cetakan kubus

f. Tongkat penumbuk

g. Mesin vibrasi/getaran

h. Sekop besar.

i. Penggaris.

j. Gelas ukur.

k. Ember.

1. Sendok semen ( cetok).

m. Seperangkat peralatan kunci.

\subsection{PENGUJIAN MATERIAL}

\section{a. AGREGAT HALUS}

Pasir yang digunakan untuk pengujian adalah pasir zonaIII dari sungai pilohayanga. Pengujian agregat halus ini dilakukan untuk mengetahui kualitas dari pasir sungai pilohayanga yang akan di gunakan sebagai material dalam pembentuk mutu beton. Pengujian yang dilakukan adalah:

1. Analisis Saringan

Analisis saringan dilakukan untuk mengetahui gradasi dan modulus kehalusan pasir zonaIII.Modulus halus diperoleh dari jumlah persen kumulatif dari butiran agregat yang tertinggal di atas satu set ayakan dan kemudian dibagi seratus (1 set ayakan \#40, \#20, \#10, \#4,8, \#2,4, \#1,2, $\# 0,60$, \#0,30 dan \#0,15 mm). Semakin besar nilai mhb, semakin besar butiran agregatnya.

2. Analisis Kadar Air

Untuk mengetahui kadar air pasir zonaIII, baik pada kondisi asli dilapangan maupun kondisi SSD. Atau dengan kata lain dapat didefinisikan sebagai perbandingan antara berat air dengan berat agregat dalam keadaan kering dengan tujuan untuk menentukan banyaknya air yang dibutuhkan dalam campuran beton.

3. Analisa Kadar Lumpur

Dilakukan untuk mengetahui kadar lumpur yang terdapat pada pasir. Untuk pengujian kadar lumpur pasir, dapat dilakukan dengan cara kocokan.

4. Kadar Organik

Pengujian kadar organik untuk menentukan bahan organik dalam agregat halus yang akan digunakan pada campuran beton. Kandungan organik akan menghambat waktu pengikatan semen.

5. Berat Jenis dan Penyerapan

Tujuan pengujian ini adalah untuk menentukan berat jenis dan absopsipada keaadaan jenuh air kering permukaan Surface Saturated Dry (SSD), untuk menetapkan besarnya komposisi volume agregat didalam merencanakan campuran beton. 


\section{b. AGREGAT KASAR}

1. Pengujian analisa saringan agregat kasar

2. Pengujian Kadar Air

3. Pengujian kandungan lumpur agregat kasar.

4. Pengujian berat jenis agregat kasar

5. Pengujian berat volume agregat kasar

6. Pengujian analisa keausan agregat kasar dengan mesin abrasi los angeles

\subsection{LANGKAH PEMBUATAN CAMPURAN DAN PENGUJIAN BETON}

a. Menakar seluruh campuran yang dibutuhkan, baik semen, pasir, dan air sesuai dengan mix design yang dibuat.

b. Memasukan bahan-bahan tersebut kedalam molen dengan urutan sebagai berikut:

- Memasukan semen dan pasir terlebih dahulu.

- Putar molen hingga yerlihat keduanya homogen.

- Memasukan air sedikit demi sedikit sambil memutar kembali molen hingga air campuran habis.

c. Memutar molen selama kurang lebih dari 10 menit agar campuran merata. Untuk memeastikan sudah merata, molen dibolak-balik kekanankekiri dengan kemiringan tertentu, namun jangan sampai menumpahkan isi molen. Setelah adukan terlihat homogen kurang lebih 3 menit, lalu tuangkan campuran diatas wadah.

d. Menuangakan campuran diatas loyang, atau ember sebanyak separuh dari isi molen untuk menguji workabilitas.

e. Pada saat sedang dilakukan pengujian workabilitas, molen tetap diputar agar tetap terjaga homogenitas dari campuran yang tersisa.

f. Lakukan pengujian nilai slump dan periksa apakah memenuhi persyaratan yang disyaratkan atau tidak (slump diisyaratkan pada penelitian ini adalah 15-7,5 mm untuk plat, balok, kolom dinding).

\subsection{PENGUJIAN WORKABILITY}

a. Campuran agregat tersebut sesegera dimasukan kedalam kerucut secra bertahap, sebanyak 3 lapisan dengan ketinggian yang sama. Setiap lapis didapatkan dengan cara ditusuk secara bebas tongkat baja berdiameter $16 \mathrm{~mm}$, panjang $60 \mathrm{~cm}$. Dilakukan sebanyak $25 \mathrm{kali}$ untuk tiap lapis.

b. Meratakan adukan pada bidang atas kerucut abrahams dan di diamkan selama 30 detik.

c. Mengangkatkerucut Abrahamssecara perlahan dengan arah vertikal keatas, diusahakan jangan sampai terjadi singgungan terhadap campuran beton.

d. Pengukuran slump dilakukan dengan membalikkan posisi Abrahams diseblah adukan. Kemudian dilakukan pengukuran sebelah adukan. Kemudian dilakukan penurunan duhitung terhadap bagian atas kerucut Abrahams .dilakukan tiga kali pengukuran dengan mistar pengukur atau meteran, kemudian hasilnya dirata-rata.

e. Nilai rata-rata menunjukkan nilai Slumpdari campuran mortar. 


\subsection{PEMBUATAN BENDA UJI KUBUS}

a. Menyiapkan cetakan kubus yang telah diolesi dengan oli.

b. Lalu mortar segara dimasukan pada cetakan kubus sesuai jumlah kubus yang ada.

c. Pengisian campuran mortar segar pada kubus dilakukan sebanyak 3 lapis yang sama, tiap lapis dilakukan model pemadatan menggunakan tungkat penusuk. Masing-masing lapis ditumbuk sebanyak 25 kali dengan alat penumbuk.

d. Kemudian diketuk-ketuk dengan palu karet pada bagian luar cetakan

e. dengan tujuan menghilangkan gelembung gelembung udara yang ada dalam cetakan.

f. Meratakan bagian samping dengan cetok, agar rata dan padat.

g. setelah penuh meratakan dan memadatkan bagian atas cetakan dengan cetak, dengan jalan agak ditekan kebawah.

h. Memberi label pada cetakan untuk mengetahui spesifikasi benda uji.

\subsection{PENGUJIAN KUAT TEKAN BETON}

a. Kubus yang di rendam dianggkat dari rendaman, kemudian dianginkan atau dilap hingga kering permukaan.

b. Menimbang dan mencatat berat sampel, kemudian diamati apakah terdapat cacat pada sampel sebagai bahan laporan.

c. Pengujian kuat tekan dengan menggunakan alat Universal Testing Machine (UTM) merk Controls.

d. Melatakan sampel ke dalam alat penguji, lalu menghidupkan mesin dan secara perlahan alat menekan sampel .

e. Mencatat hasil kuat tekan beton untuk tiap sampelnya.

\section{HASIL DAN PEMBAHASAN}

4.1. HASIL PEMERIKSAAN KARAKTERISTIK MATERIAL AGREGAT

Tabel 3 : Hasil Pemeriksaan Agregat Halus (Pasir Zona III)

\begin{tabular}{|l|c|c|c|}
\hline \multicolumn{1}{|c|}{ Nama Pengujian } & Hasil Pengujian & Spesifikasi & Satuan \\
\hline Analisa Saringan & 3.19 & $1.50-3.80$ & - \\
\hline Kadar Air & 3.70 & $3-5$ & $\%$ \\
\hline Kadar Lumpur & 3.816 & Maks 5 & $\%$ \\
\hline Kadar Organik & Bening Kekuningan & - & - \\
\hline Berat Jenis dan Penyerapan & & & \\
- BJ Apperent & 2.536 & $2.50-2.70$ & - \\
- BJ Bulk & 2.437 & $2.50-2.70$ & - \\
- BJ SSD & 2.476 & $2.50-2.70$ & - \\
- Penyerapan & 1.58 & $0.2-2.0$ & $\%$ \\
\hline Berat Isi & 1.680 & $1.6-1.9$ & $\mathrm{gr} / \mathrm{cm}^{3}$ \\
- Kondisi Padat & 1.528 & $1.6-1.9$ & $\mathrm{gr} / \mathrm{cm}^{3}$ \\
- Kondisi Gembur & \multicolumn{3}{l}{}
\end{tabular}




\subsection{HASIL PEMERIKSAAN AGREGAT KASAR (KERIKIL)}

Tabel 4 : Hasil Pemeriksaan Agregat Kasar (Batu Kerikil)

\begin{tabular}{|l|c|c|c|c|}
\hline \multirow{2}{*}{\multicolumn{1}{|c|}{ Nama Pengujian }} & \multicolumn{2}{|c|}{ Hasil Pengujian } & \multirow{2}{*}{ Spesifikasi } & \multirow{2}{*}{ Satuan } \\
\cline { 2 - 5 } & $\mathbf{2 0} \mathbf{~ m m}$ & $\mathbf{4 0} \mathbf{~ m m}$ & & \\
\hline Analisa Saringan & 7.026 & 6.607 & $6.0-7.10$ & - \\
\hline Kadar Air & 2.887 & 2.334 & $0.5-3.0$ & $\%$ \\
\hline Kadar Lumpur & 0.553 & 0.705 & Maks 1 & $\%$ \\
\hline Berat Jenis dan Penyerapan : & & & & \\
- BJ Apperent & 2.594 & 2.699 & $2.50-2.70$ & - \\
- BJ Bulk & 2.485 & 2.558 & $2.50-2.70$ & - \\
- BJ SSD & 2.527 & 2.610 & $2.50-2.70$ & - \\
- Penyerapan & 1.700 & 2.050 & $0.2-4.0$ & $\%$ \\
\hline Berat Isi : & & & & \\
- Kondisi Padat & 1.618 & 1.778 & $1.6-1.9$ & $\mathrm{gr} / \mathrm{cm}^{3}$ \\
- Kondisi Gembur & 1.792 & 1.592 & $1.6-1.9$ & $\mathrm{gr} / \mathrm{cm}^{3}$ \\
\hline Keausan Agregat Kasar & 25.12 & 20.12 & Maks 27 & $\%$ \\
\hline
\end{tabular}

Dari hasil pengujian material agregat kasar berupa batu kerikil yang diambil dari sungai Bionga, layak digunakan sebagai material pembentuk beton karena masih memenuhi Syarat Mutu menurut SK SNI S - 04 - 1989 - F dan ASTM.

4.3. PRESENTASE GABUNGAN AGREGAT

Tabel 5 : Penggabungan Agregat Metode Analisis

\begin{tabular}{|l|c|c|c|}
\hline \multirow{2}{*}{ Bahan } & \multicolumn{2}{|c|}{$\begin{array}{c}\text { Persentase Gabungan } \\
\text { agregat }\end{array}$} & \multirow{2}{*}{ Satuan } \\
\cline { 2 - 3 } & $\mathbf{2 0} \mathbf{~ m m}$ & $\mathbf{4 0} \mathbf{~ m m}$ & \\
\hline Agregat Halus (Pasir Zona III) & 37,65 & 38,08 & \multirow{2}{*}{$\%$} \\
\hline Agregat Kasar (Batu Kerikil) & 62,35 & 61,92 & \\
\hline
\end{tabular}

\subsection{RANCANGAN CAMPURAN BETON}

Tabel 6 : Proporsi Campuran beton untuk 1 buah kubus

\begin{tabular}{|c|c|c|c|}
\hline \multirow{2}{*}{ Bahan } & \multirow{2}{*}{ Sat } & \multicolumn{2}{|c|}{ Benda Uji } \\
\cline { 3 - 4 } & & Kerikil 20 $\mathbf{~ m m}$ & Kerikil 40 $\mathbf{~ m m}$ \\
\hline Air & $\mathrm{Kg}$ & 0,071 & 0,607 \\
\hline Semen & $\mathrm{Kg}$ & 1,075 & 0,956 \\
\hline Agregat Halus & $\mathrm{Kg}$ & 2,253 & 2,560 \\
\hline Agregat Kasar & $\mathrm{Kg}$ & 3,766 & 4,240 \\
\hline
\end{tabular}

4.5. HASIL PENGUJIAN KUAT TEKAN BETON

Tabel 7 : Hasil Pengujian Kuat Tekan Beton

\begin{tabular}{|c|c|c|c|c|}
\hline \multirow{2}{*}{$\begin{array}{c}\text { Kuat Tekan } \\
\text { Rencana }\end{array}$} & \multirow{2}{*}{$\begin{array}{l}\text { Umur } \\
\text { (hari) }\end{array}$} & \multirow{2}{*}{$\underset{\text { (cm) }}{\text { Slump }}$} & Kerikil $20 \mathrm{~mm}$ & Kerikil $40 \mathrm{~mm}$ \\
\hline & & & $\sigma^{\prime} \mathbf{b}\left(\mathrm{Kg} / \mathrm{cm}^{2}\right)$ & $\sigma^{\prime} b\left(\mathrm{Kg} / \mathrm{cm}^{2}\right)$ \\
\hline \multirow{5}{*}{$\mathrm{K}-225$} & 3 & 4 & 115,83 & 128,85 \\
\hline & 7 & 4 & 166,32 & 181,27 \\
\hline & 14 & 4 & 213,76 & 239,13 \\
\hline & 21 & 4 & 263,50 & 287,36 \\
\hline & 28 & 4 & 311,89 & 334,46 \\
\hline
\end{tabular}




\subsection{PEMBAHASAN PENGUJIAN AGREGAT \\ a. Analisa Saringan}

1. Agregat Halus

Gambar 2 : Grafik Gradasi Agregat Halus

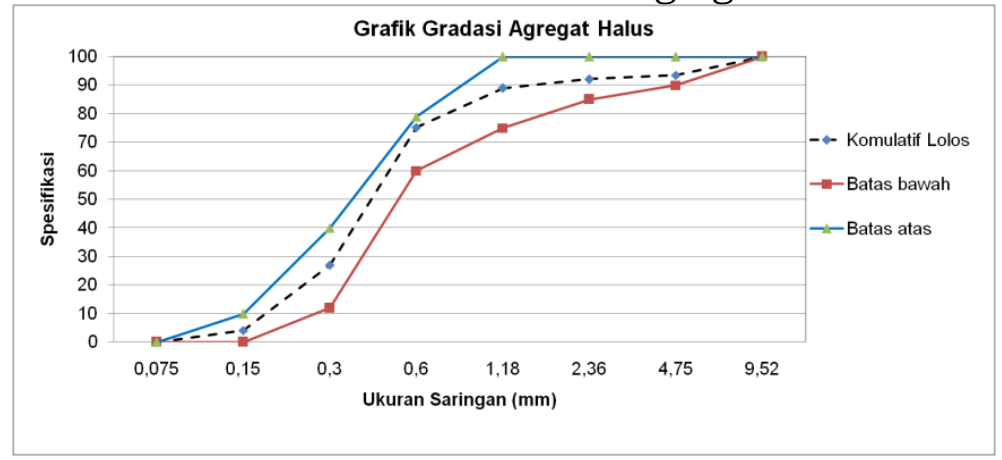

Dari hasil pengujian yang dilakukan menunjukkan gradasi untuk agregat halus berada dalam batas-batas yang disyaratkan dalam spesifikasi SK.SNI.T-15-1990-03, dimana gradasinya masuk pada Zone III yang merupakan daerah gradasi pasir agak halus.Modulus Halus Butir (MHB) merupakan suatu indeks yang dipakai untuk menjadi ukuran kehalusan atau kekasaran butir-butir agregat.Menurut SII.0052 pasir mempunyai MHB antara 1.50 - 3.80 dan setelah dilakukan pengujian pada pasir dari Sungai Pilohayanga diperoleh MHB sebesar 3,190.Jadi tingkat kekasaran ataupun kehalusan dari pasir ini masih masuk dalam batasan yang sudah disyaratkan.

2. Agregat Kasar

Gambar 3 : Grafik Gradasi Agregat Kasar

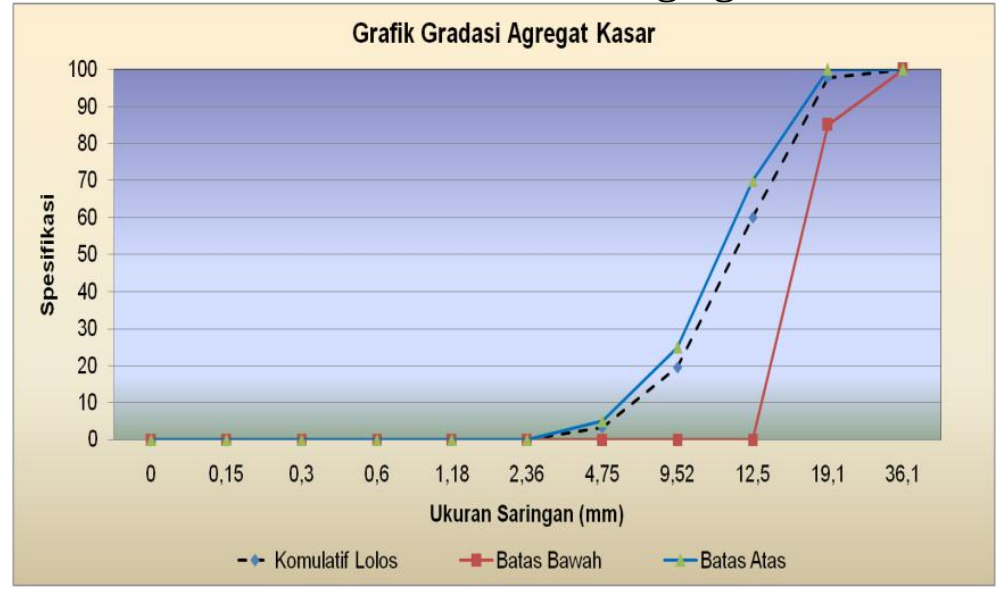

Gradasi Agregat Kasar 20 mm 


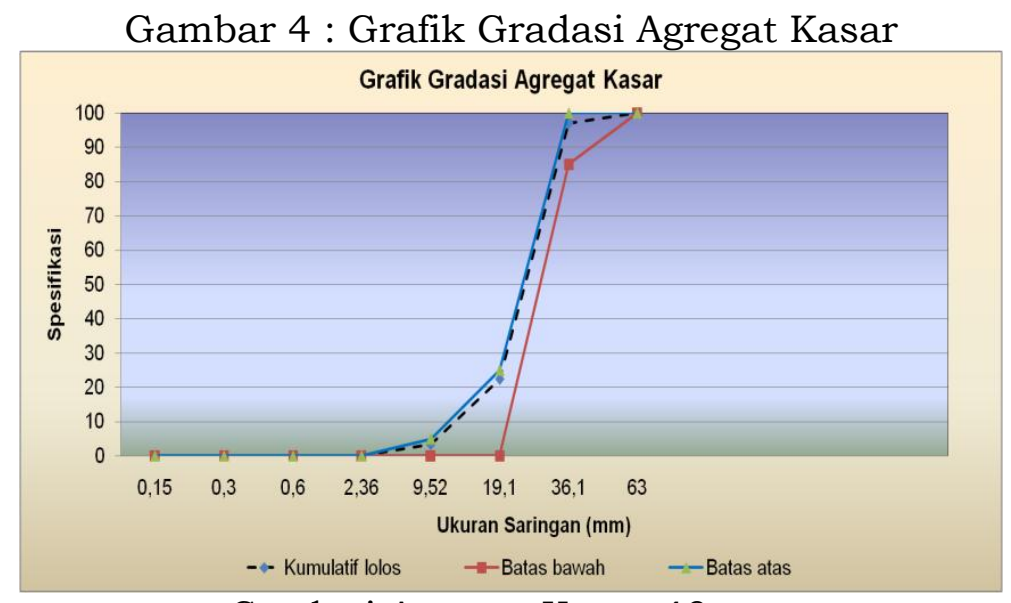

Gradasi Agregat Kasar $40 \mathrm{~mm}$

Dari hasil pengujian yang dilakukan menunjukkan agregat kasar yang digunakan pada pengujian ini yaitu batu kerikil yang masuk pada syarat gradasi untuk agregat kasar dengan ukuran butir maksimum $40 \mathrm{~mm}$. Sedangkan MHB yang diperoleh batu Kerikil untuk $20 \mathrm{~mm}$ adalah 7,026 dan kerikil $40 \mathrm{~mm}$ adalah sebesar 6.607. Jadi MHB batu kerikil masih masuk dalam syarat batas yang diberikan SII.0052 sebesar $6.00-7.10$.

\section{b. Kadar Air}

Dari hasil pengujian didapat kadar air yang terkandung dalam agregat halus adalah 3,70 \%. Dan untuk kadar air agregat kasar berupa kerikil 40 $\mathrm{mm}$ diperoleh nilai sebesar 2,334\% dan untuk kerikil $20 \mathrm{~mm}$ sebesar 2,887 $\%$. Hasil dari pengujian kadar air yang terkandung dalam agregat sangat perlu untuk dipakai dalam merencanakan campuran beton dan juga untuk mengkoreksi proporsi campuran.

\section{c. Kadar Lumpur}

Menurut SII.0052 jumlah kandungan kotoran pada agregat tidak boleh lebih dari 5\% untuk agregat halus dan tidak boleh lebih dari $1 \%$ untuk agregat kasar. Pada pengujian yang telah dilakukan didapatkan kadar lumpur dalam agregat halus yaitu 3,816 \% dan pada agregat kasar yaitu kerikil 20 mm sebesar 0,5533 \% sedangkan pada ukuran $40 \mathrm{~mm}$ adalah 0,7053 \%.

\section{d. Berat Jenis dan Penyerapan Agregat}

Untuk agregat kasar dan agregat halus yang digunakan termasuk dalam agregat normal maka disyaratkan berat jenis antara 2.5-2.7. Pada pengujian ini diperoleh berat jenis agregat halus sebesar 2.536 untuk agregat kasar (Kerikil) $20 \mathrm{~mm}$ sebesar 2.594 dan untuk $40 \mathrm{~mm}$ adalah sebesar 2.699.Berat jenis agregat juga berhubungan dengan penyerapan/absorpsi agregat yaitu pada beton normal menurut ASTM untuk agregat halus dibatasi antara $0.2 \%$ $2 \%$ dan untuk agregat kasar antara $0.2 \%$ - 4\%. Data yang diperoleh untuk agregat halus absorpsinya sebesar $1.58 \%$ dan agregat kasar (kerikil) $20 \mathrm{~mm}$ sebesar 1,700 \%, untuk $40 \mathrm{~mm}$ sebesar 2,050 \%. Hal ini menunjukkan bahwa kedua agregat ini dapat digunakan tanpa membasahi atau mengeringkan terlebih dahulu untuk memperoleh campuran yang digunakan.

\section{e. Berat Isi}

Dari hasil pemeriksaan yang dilakukan terhadap agregat halus maupun agregat kasar menunjukkan bahwa berat isi dari agregat dalam keadaan lepas 
atau padat tidak terlalu beda jauh. Hal ini terjadi karena gradasi kedua agregat yang tersusun baik, sehingga agregat saling mengisi. Untuk berat isi agregat halus kondisi gembur 1,528 gram/ $\mathrm{cm}^{3}$ dan dalam kondisi padat 1,680 gram $/ \mathrm{cm}^{3}$, sedangkan untuk berat isi agregat kasar (kerikil) $20 \mathrm{~mm}$ kondisi gembur $1,618 \mathrm{gram} / \mathrm{cm}^{3}$, dalam kondisi padat $1,792 \mathrm{gram} / \mathrm{cm}^{3}$. Untuk $40 \mathrm{~mm}$ kondisi gembur $1,592 \mathrm{gram} / \mathrm{cm}^{3}$ dalam kondisi padat sebesar $1,778 \mathrm{gram} / \mathrm{cm}^{3}$.

\section{f. Keausan Agregat/Abrasi}

Pengujian keausan pada agregat kasar dengan sampel bahan uji yang masing-masing 2500gr agregat yang tertahan pada saringan $3 / 4$ dan 2500 gr yang tertahan pada saringan nomor $1 / 2$ dengan 500 jumlah putaran serta menggunakan 11 bola baja. Hasil dari pengujian keausan agregat kasar untuk $20 \mathrm{~mm}$ sebesar 25,12\% sedangkan untuk $40 \mathrm{~mm}$ sebesar 20,12\%. ini berarti agregat kasar kerikil ini memenuhi syarat sesuai standar SNI yakni untuk beton tidak melebihi $27 \%$.

\section{g. Pengujian Kuat Tekan BetonMutu 225}

Hasil pengujian Kuat Tekan beton diperoleh nilai kuat tekan rata-rata umur 28 hari untuk beton dengan bahan agregat halus pasir zona III dan agregat kasar (karikil) $20 \mathrm{~mm}$ yaitu $311,89 \mathrm{~kg} / \mathrm{cm}^{2}$, serta beton dengan bahan pasi zona III dan kerikil $40 \mathrm{~mm}$ memperoleh hasil kuat tekan sebesar 334,46 $\mathrm{kg} / \mathrm{cm}^{2}$.

\section{KESIMPULAN}

Hasil penelitian beton dengan bahan pasir zona III dan kerikil ukuran 20 mm menunjukan nilai kuat tekan sebesar $311,89 \mathrm{Kg} / \mathrm{cm}^{2}$. Kemudian sampel beton dengan bahan pasir zona III dan kerikil ukuran $40 \mathrm{~mm}$ menunjukan nilai kuat tekan sebesar $334,46 \mathrm{Kg} / \mathrm{cm}^{2}$. Dari hasil ini maka dapat disimpulkan bahwa campuran pasir zona III dengan kerikil berukuran $40 \mathrm{~mm}$ memiliki nilai kuat tekan beton yang lebih besar dibandingkan dengan $20 \mathrm{~mm}$.

\section{DAFTAR PUSTAKA}

Alizar, 2001, TEKNOLOGI BAHAN KONTRUKSI, Pusat Pengembangan Bahan Ajar UMB Jakarta.

Anton, 2007, TEKNOLOGI BETON, Penerbit CV Andi Offset, Yogyakarta.

Mulyono, Tri, 2003, TEKNOLOGI BETON, Andi Offset, Yogyakarta.

Nugraha, P, 2007, TEKNOLOGI BETON, Penerbit CV Ansi Offset, Yogyakarta.

Riyadi, M, 2005, TEKNOLOGI BAHAN 1, Jurusan Teknik Sipil Politeknik Negeri Jakarta, Jakarta.

Spesifikasi Umum (2010). Struktur Beton, Kemenrian Pekerjaan Umum Bina Marga.

SNI 03-2834-1993 (1993), TATA CARA PEMBUATAN RENCANA CAMPURAN BETON NORMAL, Pusjatan-Balitbang PU.

PEDOMAN PELAKSANAAN PRAKTIKUM LABORATORIUM STRUKTUR DAN BAHAN, Universitas Gorontalo. 